\begin{tabular}{|c|c|}
\hline $\begin{array}{l}\text { MPW ACriva } \\
\text { M. E. Browne, } \\
\text { Suite 204, } 895 \text { Fort St., }\end{array}$ & $\begin{array}{l}\text { D. P. Richards, } \\
\text { Canada Dept. of Forestry, } \\
238 \text { Sparks St., } \\
\text { Ottawa, Ont. }\end{array}$ \\
\hline Victoria, B.C. & Glen Young, \\
\hline $\begin{array}{l}\text { S. C. Chafe, } \\
\text { Whitbourne, Nfld. }\end{array}$ & $\begin{array}{l}4403 \text { Acadie, } \\
\text { Pierrefonds, Quebec }\end{array}$ \\
\hline $\begin{array}{l}\text { J. T. Davis, } \\
\text { Irvine Road, R.R. \#2, }\end{array}$ & $\begin{array}{l}\text { Robert E. Beard, } \\
\text { Port Renfrew, B.C. }\end{array}$ \\
\hline St. C & $\begin{array}{l}\text { William C. Calvert, } \\
\text { Lake Saint Peter, Ontario }\end{array}$ \\
\hline $\begin{array}{l}69 \text { Fraser Ave., } \\
\text { Edmundston, N.B. }\end{array}$ & \\
\hline $\begin{array}{l}\text { F. R. Moore, } \\
\text { Room 509, Norquay Bldg., } \\
\text { Winnipeg 1, Man. }\end{array}$ & $\begin{array}{l}\text { Sioux Lookout, Ontario } \\
\text { Neils Hauffe, }\end{array}$ \\
\hline $\begin{array}{l}\text { W. G. Muir, } \\
\text { Nimpkish Camp, }\end{array}$ & Senneville, P.Q. \\
\hline $\begin{array}{l}\text { L. D. Paakar, } \\
\text { Giscome, B.C. }\end{array}$ & $\begin{array}{l}\text { Cillam J. Gilpin, } \\
\text { Powell River Ltd., } \\
\text { Franklin River Div., }\end{array}$ \\
\hline $\begin{array}{l}\text { G. Paille, } \\
\text { Forest Montmorency, } \\
\text { A/S Faculte de Foresterle, } \\
\text { Universite Laval, } \\
\text { Quebec, Que. }\end{array}$ & $\begin{array}{l}\text { John H. Johnson, } \\
\text { Box } 133 \text {, } \\
\text { Harrison Hot Springs, B.C. }\end{array}$ \\
\hline $\begin{array}{l}\text { W. R. Parks, } \\
\text { 648-22nd St. W., } \\
\text { Prince Albert, Sask. }\end{array}$ & $\begin{array}{l}\text { Frederick J. Lowenberger, } \\
\text { Box 51, } \\
\text { Kelsey Bay, B.C. }\end{array}$ \\
\hline $\begin{array}{l}\text { J. R. Powell, } \\
\text { Box } 2076, \\
\text { Hinton, Alta. }\end{array}$ & $\begin{array}{l}\text { David John Morgan, } \\
\text { c/o Mackenzie Forest Ser., } \\
\text { Fort Smith, N.W.T. }\end{array}$ \\
\hline $\begin{array}{l}\text { L. Pringle, } \\
\text { orest \& Fore } \\
\text { A.O., Rome, }\end{array}$ & $\begin{array}{l}\text { Daryl Brian Paver, } \\
2361 \text { Cavendish Avenue, } \\
\text { Victoria, B.C. }\end{array}$ \\
\hline
\end{tabular}

Robert Norman Russell, 5070 Willow Street, Vancouver, B.C.

Gordon A. Van Sickle, 340 University Avenue, Fredericton, N.B.

Stanley J. Williamson, Box 838

The Pas, Manitoba

\section{NEW APFIIIATY} MTMBERS

R. M. Carroll, Gander, Nffld.

E. S. Clowater, Grand Manan, B.C.

W. A. Edwards, $867 \mathrm{I} / 2$ Isquimalt Road, Victoria, B.C. Morris Millar, F.A.O. Terme Di Caracalla me, Italy

\section{J. B. Santon,} Petawawa Forest Exp. Stn., Chalk River, Ont.

H. G. Taylor, St. Johns, Nfid. R. A. Turner, Box 132, Gregor Robert Turner, Port Renfrew, B.C. 